\title{
Targeting Vascular Endothelial Growth Factor Blockade: Ascites and Pleural Effusion Formation
}

\author{
H.M.W. Verheul, ${ }^{\text {a }}$ K. Hoekman, ${ }^{\text {a }}$ A.S. Jorna, ${ }^{\text {a }}$ E.F. Smit, ${ }^{\text {b H.M. Pinedo }}{ }^{\text {a }}$

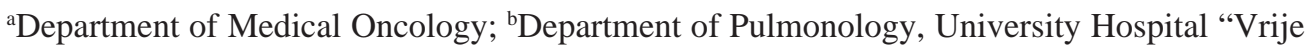 \\ Universiteit," Amsterdam, The Netherlands
}

Key Words. Ascites · Pleural effusion · Vascular endothelial growth factor

\begin{abstract}
Primary Purpose. Formation of ascites and pleural effusion (PE) is a common problem for patients with advanced-stage cancer. These fluid accumulations cause severe symptoms such as abdominal distention, shortness of breath, cachexia, anorexia, and fatigue. Preclinical models have demonstrated that vascular endothelial growth factor (VEGF) plays a pivotal role in the accumulation of malignant PE or ascites. This study investigated whether blockade of VEGF activity would reduce biological activity of PE and ascites on endothelial cells of cancer patients.
\end{abstract}

Patients and Methods. The activity of VEGF in PE and ascites of 58 patients (39 with $P E$ and 19 with ascites) was measured. An endothelial cell proliferation assay with human umbilical vein endothelial cells was used to determine the biological activity of ascites and PE.

Results. VEGF concentrations ranged from 67-6,245 $\mathrm{pg} / \mathrm{ml}$. A significantly higher concentration of VEGF was detected in the ascites and $\mathrm{PE}$ of patients with cancer (median, $1,290 \mathrm{pg} / \mathrm{ml}$ ) than in patients with nonmalignant disease (median, $250 \mathrm{pg} / \mathrm{ml} ; \boldsymbol{p}=0.02$ ). Of the $58 \mathrm{PE}$ and ascites samples, 41 were biologically active, based on a two- to fourfold stimulation of endothelial cell proliferation in 72 hours. VEGF concentrations were significantly higher in the biologically active samples compared with the 17 nonactive samples $(2,056$ $\mathrm{pg} / \mathrm{ml}$ versus $771 \mathrm{pg} / \mathrm{ml} ; \boldsymbol{p}=\mathbf{0 . 0 2}$ ). Coincubation of the samples with either a neutralizing polyclonal antibody against VEGF or SU5416, a small molecule inhibitor of the VEGF receptor Flk-1/KDR, inhibited endothelial cell proliferation by $66 \%$ and $100 \%$, respectively. The inhibition caused by the antibody and that caused by SU5416 correlated significantly $(r=0.8, p<0.001)$.

Conclusion. We conclude that malignant ascites and PE contain high levels of biologically active VEGF. This study strongly supports the hypothesis that blockade of VEGF, such as that afforded by SU5416, may benefit cancer patients with recurrent ascites or PE formation. The Oncologist 2000;5( suppl 1):45-50

\section{INTRODUCTION}

The formation of ascites and pleural effusion (PE) in patients with advanced-stage cancer is a difficult problem in clinical oncology. Ascites and PE cause serious symptoms including abdominal distention, shortness of breath, cachexia, anorexia, and fatigue. The formation of ascites and PE mostly occurs in advanced-stage disease. Currently, alternatives for cytotoxic therapy against ascites and PE include diuresis, salt restriction, pleurodesis, and peritoneovenous shunts [1-6].

The etiology of PE and ascites has traditionally been attributed to insufficient lymph drainage caused by tumor spread into draining lymph vessels [7]. However, in 1986, Senger et al. suggested an alternative possibility [8]. They isolated vascular permeability factor (VPF) from ascites in tumor-bearing animals and hypothesized that this factor was responsible for the fluid accumulations. A few years later, vascular endothelial growth factor (VEGF) was discovered as a potent angiogenesis stimulator and recognized to be VPF $[9,10]$.

Five different VEGF mRNAs have been detected encoding the isoforms $\mathrm{VEGF}_{121}, \mathrm{VEGF}_{145}, \mathrm{VEGF}_{165}, \mathrm{VEGF}_{189}$, and $\mathrm{VEGF}_{206}[11]$. The receptors for VEGF are mainly confined to the endothelial cells and belong to the tyrosine kinase receptor family [11]. Two specific endothelial cell receptors for VEGF have been identified, VEGFR-1 (Flt-1) and VEGFR-2 (Flk$1 / \mathrm{KDR}$ ) [12-15]. Flk-1/KDR appears to be the receptor that is mainly involved in the angiogenesis process [15-17]. 
Several preclinical in vivo studies [18-20] have clearly demonstrated that ascites and PE formation induced by tumor cells contain high concentrations of VEGF. Blockade of the VEGF activity in mice using anti-VEGF antibodies $[21,22]$ or VEGF receptor tyrosine kinase inhibitors [20] led to significantly reduced fluid accumulations. In addition, use of anti-VEGF antibodies was associated with prolonged survival in MM2 breast carcinoma-bearing mice compared with controls [21].

In clinical studies [23-25], high concentrations of VEGF have been found in malignant PE and ascites, while lower concentrations were detected in ascites and PE from nonmalignant diseases such as congestive heart failure [25] or liver cirrhosis [23].

These findings have prompted the hypothesis that antiVEGF therapy could block ascites and PE formation in cancer patients. However, no data have been reported that VEGF in ascites and PE is biologically active. Therefore, we studied the concentrations of VEGF in ascites and PE of patients with malignancies, investigated the biological activity of these specimens, and evaluated whether an anti-VEGF antibody and a VEGF receptor tyrosine kinase inhibitor, SU5416 (SUGEN, Inc.; South San Francisco, CA), could block VEGF activity. Biological activity was tested in an endothelial cell proliferation assay.

\section{Patients And Methods}

\section{Patients}

$\mathrm{PE}$ and ascites were aspirated on clinical indication from 58 patients, 11 patients without a malignancy and 47 with a malignancy. Malignancies included gastrointestinal tumors $(n=10)$, lung tumors $(n=7)$, breast cancers $(n=9)$, and ovarian cancers $(n=6)$, and 15 patients had melanoma, soft tissue sarcoma, mesothelioma, or unknown primaries. The 11 patients with nonmalignant disease suffered from an infection, heart failure, autoimmune disease, or a benign tumor such as a thymoma. Upon informed consent from patients, $\sim 10 \mathrm{ml}$ of aspirations from PE or ascites were immediately centrifuged at 3,500 rpm, and the supernatant was stored at $-80^{\circ} \mathrm{C}$. Because ascites and PE formation recurred in some patients, repeated aspirations were necessary; up to four different samples from a single patient were stored.

\section{Methods}

\section{VEGF Concentrations}

VEGF concentrations were measured with a quantitative sandwich enzyme immunoassay (R\&D Systems; Abingdon, UK), according to the manufacturer's instructions.

\section{Endothelial Cell Culture}

Human umbilical vein endothelial cells (HUVECs) were obtained by a standard procedure [26]. Endothelial cells were cultured on fibronectin $(10 \mu \mathrm{g} / \mathrm{ml})$-coated plates in endothelial cell growth medium (M199 containing 10\% human serum, $10 \%$ fetal calf serum [FCS], 5 units $/ \mathrm{ml} \mathrm{heparin,}$ $1 \%$ penicillin [200 $\mathrm{U} / \mathrm{ml}], 1 \%$ streptomycin [200 $\mu \mathrm{g} / \mathrm{ml}], 1 \%$ glutamine $[290 \mathrm{~g} / \mathrm{l}]$, and $50 \mu \mathrm{g} / \mathrm{ml}$ endothelial cell growth factor [ECGF] derived from bovine hypothalamus). Only cells from the first three cell passages were used in all experiments.

\section{Proliferation Assay}

HUVECs were plated in a density of 3,000 cells/well on precoated 96-well plates in $100 \mu$ l endothelial cell medium containing 5\% FCS and 5\% newborn calf serum with no ECGF added. The following day, $100 \mu \mathrm{l}$ of PE or ascites (concentration range, 3\%-100\%) in endothelial cell growth medium without serum were added. After $72 \mathrm{~h}$, the 3-(4,5dimethylthiazol-2-yl)-2,5-diphenyltetrazoliumbromide (MTT) assay test was performed according to standard procedures. In each, experimental conditions were tested in triplicate.

\section{Inhibition Experiments}

Endothelial cell proliferation stimulated by PE or ascites in a final concentration of $25 \%$ was either coincubated with a polyclonal antibody against VEGF ( $1 \mu \mathrm{g} / \mathrm{ml}$, R\&D Systems) or with SU5416 in a concentration of $1 \mu \mathrm{M}$. SU5416 was provided by SUGEN, Inc. A polyclonal rabbit IgG was used as a negative control for the polyclonal antibody against VEGF.

\section{Statistical Analysis}

Statistical analysis was performed with SPSS software (SPSS, Inc.; Chicago, IL). For the correlation coefficient, the Spearman rank correlation test was used. Statistical differences were calculated with the $t$ test.

\section{RESUlts}

\section{VEGF Concentrations}

VEGF concentrations were significantly higher in the 19 cancer patients with ascites and the 28 cancer patients with PE (median, 1,290 pg/ml; range, 67-6,245 pg/ml) compared with 11 patients with nonmalignant disease (median, 250 $\mathrm{pg} / \mathrm{ml}$; range, $90-2,167 \mathrm{pg} / \mathrm{ml} ; p=0.02)$. Total protein concentrations did not differ significantly $(p=0.7)$ in patients with a malignant versus nonmalignant disease. VEGF and bFGF concentrations did not differ significantly between malignancies.

\section{Proliferation Assay}

In a 72-hour proliferation assay, samples with high VEGF concentrations increased the proliferation rate of 
HUVECs to a fourfold maximum. A rather weak, but significant, correlation between the VEGF concentration and the induction of proliferation was found $(r=0.4, p<0.01)$. Figure 1 depicts a representative experiment with six samples of PE and ascites. The samples that induced a two- to fourfold proliferation contained significantly higher VEGF concentrations compared with the inactive samples (Fig. 2).

\section{Inhibition Assay}

When $25 \%$ of the samples were coincubated with either a blocking antibody against VEGF or the VEGF tyrosine kinase inhibitor SU5416, up to $100 \%$ of the biological activity of these fluids was blocked. Anti-VEGF antibody and SU5416 in concentrations of $1 \mu \mathrm{g} / \mathrm{ml}$ and $1 \mathrm{mM}$, respectively, were used because these concentrations blocked the proliferation of $25 \mathrm{ng} / \mathrm{ml}$ of recombinant human VEGF but had no effect on recombinant human bFGF $(12.5 \mathrm{ng} / \mathrm{ml})$-induced proliferation. In the proliferation assay, the inhibitory effect of the anti-VEGF antibody correlated highly with the inhibitor effect of SU5416 ( $r=$ $0.8, p<0.001$, Fig. 3).

\section{DISCUSSION}

The results of this study strongly support the hypothesis that VEGF is important for the formation of ascites and PE in patients with cancer, confirmed that ascites and PE from cancer patients contain higher VEGF concentrations than those obtained from patients with nonmalignant disease, and also showed that this VEGF is biologically active in a proliferation assay of HUVECs. Therefore, it may be expected that in a subpopulation of patients with

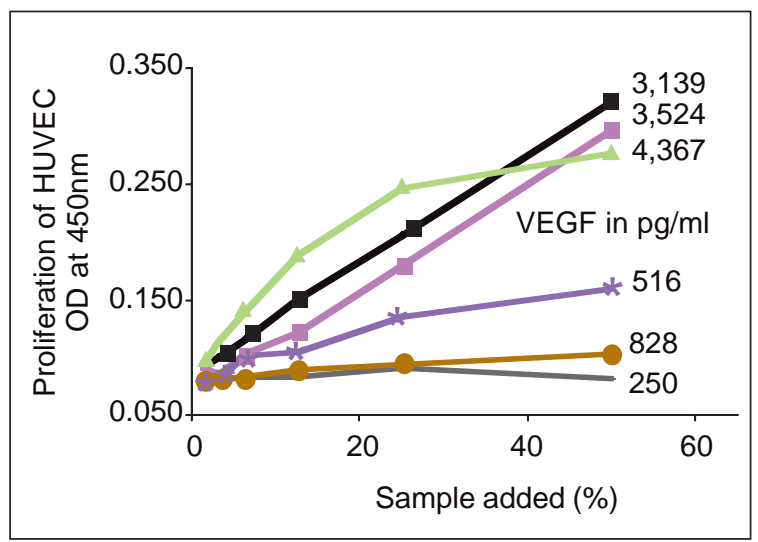

Figure 1. Stimulation of human vascular endothelial cells by ascites and pleural effusion $(\boldsymbol{P E})$. The effect on proliferation of coincubation of 0\%-50\% of ascites or PE samples with HUVECs for 72 hours was measured by 3(4,5-dimethyliazol-2-y-l)-2,5-diphenyltetrazolium bromide. A zero- to fourfold proliferation was induced by these fluids and correlated with their VEGF contents $(\mathrm{p}=0.05)$. A representative experiment is shown in this figure. $O D=$ optical density. ascites or PE containing high concentrations of VEGF, this endothelial growth factor is at least partly responsible for the fluid accumulation. The VEGF tyrosine kinase receptor blocker SU5416 could inhibit the proliferation of HUVECs induced by ascites and PE to a similar extent as a blocking antibody against VEGF. We therefore conclude

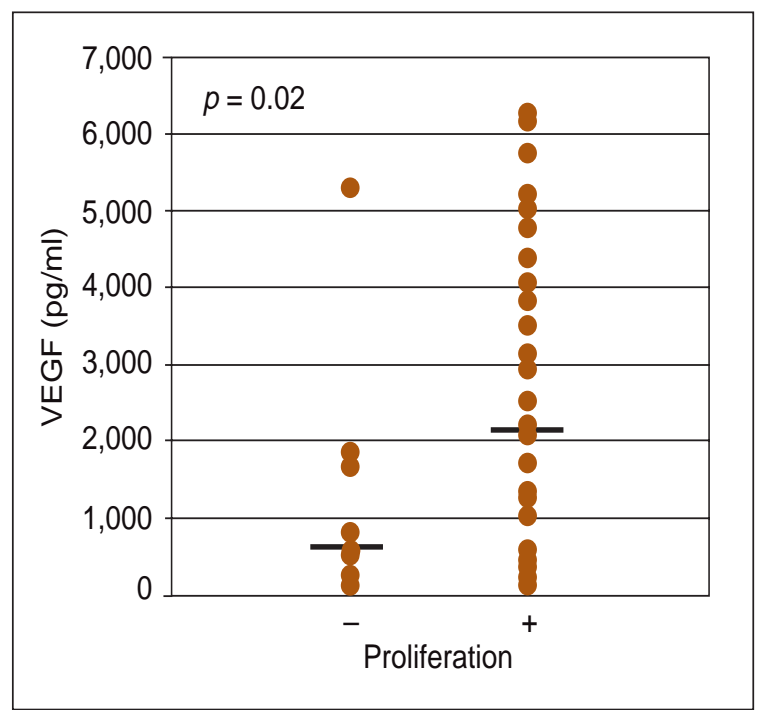

Figure 2. Effect of ascites or pleural effusion on human vascular endothelial cell proliferation relative to vascular endothelial growth factor (VEGF) content. The difference between VEGF concentrations in samples that induced a two-to fourfold proliferation $(+)$ versus samples that were inactive in the proliferation assay (-) compared with baseline proliferation is shown. The VEGF concentrations were significantly different between the active and inactive samples $(\mathrm{p}=0.02)$.

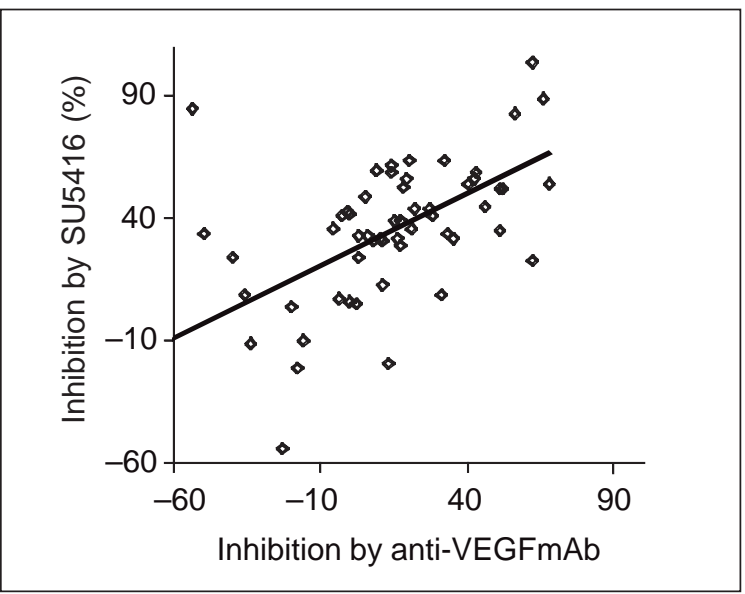

Figure 3. Correlation between inhibitory effects of SU5416 and the anti-vascular endothelial growth factor (VEGF) antibody on human vascular endothelial cell proliferation. A significant correlation $(\mathrm{r}=0.8, \mathrm{p}<0.001)$ was found between the relative inhibition (\%) of ascites/PE-induced human umbilical vein endothelial cell (HUVEC) proliferation by SU5416 and by the anti-VEGF antibody (anti-VEGFmAb). 
that treatment with SU5416, or another agent that blocks the VEGF pathway, may benefit patients with recurrent ascites and PE formation.

Although VEGF concentrations are significantly higher in effusions of patients with malignant disease, the overlap in the concentration of VEGF between malignant and nonmalignant disease is rather large [25]. Therefore, VEGF concentration may not be a useful parameter for discriminating between nonmalignant and malignant disease.

Ascites and PE formation have often been assumed to be due to inadequate lymph drainage resulting from infiltration of tumor tissue into the lymphatics [7]. However, if blockage of the lymphatic vessels were the primary cause, the pleural fluids would be transudate rather than exudate (high protein content), as seen in fluids associated with malignancies [25]. Our data support this statement because high levels of VEGF in these fluid accumulations are biologically active in vitro and thus presumably active in vivo. Although it is uncertain that VEGF is the primary cause of malignant ascites and PE formation, it can be assumed that VEGF at least contributes significantly.

In addition to VEGF, other cytokines and factors, including lysophosphatidic acid [27] and interleukin 8 [28], have been found in high concentrations in malignant ascites and/or PE. However, these factors have not been tested for their in vitro activity on endothelial cells. VEGF appears to be the only factor that induces permeability in vivo and is present in high amounts in these fluids.

It is noteworthy that in the study by Thickett et al. [24], VEGF concentrations in PE were higher in empyema than in malignant disease $(4,651 \mathrm{pg} / \mathrm{ml}$ versus $2,500 \mathrm{pg} / \mathrm{ml}$, respectively). In our study, PE obtained from one patient with empyema also contained a high concentration of VEGF $(1,637 \mathrm{pg} / \mathrm{ml})$. Additionally, among the other patients with nonmalignant diseases, one patient with tuberculosis infection also had a high VEGF concentration $(2,167 \mathrm{pg} / \mathrm{ml})$. Both empyema and tuberculosis, when left untreated, cause fibrotic lesions [29-31]. In tumors, VEGF has been shown to induce endothelial fenestration $[32,33]$ that can lead to extravascular fibrin deposition [11, 34, 35]; this may also be true for the fibrotic lesions observed in empyema and tuberculosis.

The permeability effect of VEGF is expected to play an important role in the angiogenic process of solid tumors and in the formation of ascites and PE. In addition, malignant cysts formed in ovarian cancer contained elevated levels of VEGF $(38.5 \pm 8.2 \mathrm{ng} / \mathrm{ml})$ [36]. Fluid cavities of soft tissue sarcomas also contained VEGF (median, $18 \mathrm{ng} / \mathrm{ml}$; range, 0.3-345 ng/ml) [37], which may suggest an important role for VEGF. VEGF also seems to be involved in extravascular fluid accumulations in rheumatoid arthritis [38]. High levels of VEGF were detected in the synovial fluids of rheumatoid joints.

The permeability activity of VEGF is based on the initial in vivo findings of Senger et al. [8] and on subsequent in vivo experiments. To the best of our knowledge, no study to date has been published showing that VEGF induces permeability of endothelial cells for plasma proteins in vitro. We developed an in vitro permeability assay for plasma proteins $(30-70 \mathrm{kD})$ in a transwell system with a confluent layer of HUVECs and used it to test the activity of recombinant human VEGF (data not shown). We failed to demonstrate a reproducible permeability effect of recombinant human VEGF in vitro, indicating that an essential factor or cofactor of the in vivo situation is missing in this assay. In a study by Wang et al. [39], VEGF induced permeability in vitro, but permeability was only observed for $\left[{ }^{14} \mathrm{C}\right]$ sucrose (molecular weight, $400 \mathrm{D}$ ); no permeability was detected with radiolabeled albumin. The implication of VEGF-induced leakage of small molecules is unclear, since the importance of VEGF-induced permeability in vivo is related to larger plasma proteins. It is too early to make any definite conclusions; further research is needed to explore the essential difference between the in vivo and in vitro situations.

Finally, the correlation between the inhibitory effects of the anti-VEGF antibody and SU5416 strongly suggests that the VEGF pathway is mainly responsible for the PE/ascitesinduced proliferation of the HUVECs. Because SU5416 inhibited up to $100 \%$ of the proliferation induced by these samples, SU5416 treatment may be of interest for patients with recurrent ascites and PE. Since outpatient treatment for patients with advanced-stage disease is often difficult, the development of an oral formulation may have additional benefit in the management of this patient population.

In conclusion, one may expect that in a subpopulation of patients with malignant ascites or PE containing high concentrations of VEGF, this growth factor is responsible for the fluid accumulation and that these patients may benefit from anti-VEGF therapy. Just recently, we initiated a clinical study in which the VEGF tyrosine kinase inhibitor SU5416 will be tested for its activity against recurrent $\mathrm{PE}$ or ascites formation. In addition to the main question of whether prolonged treatment with SU5416 prevents or inhibits reaccumulation of ascites or PE in cancer patients, two other interesting questions need to be answered in this study. The first is whether the effect of VEGF on reaccumulation of malignant fluid can be used as a marker for the biological activity of SU5416 in the patient. The second question is whether the VEGF measurements will predict the effect of SU5416 in patients with recurrent fluid formations. 


\section{REFERENCES}

1 Rustgi AK, Rotolo FS, Peete WP et al. Successful management of late-onset primary lymphatic hypoplasia. Surgery 1985;97:714-720.

2 Reshad K, Inui K, Takeuchi Y et al. Treatment of malignant pleural effusion. Chest 1985;88:393-397.

$3 \mathrm{Li} \mathrm{KW}$, Wong WS. Double valve Denver peritoneal venous shunt used in ovarian malignant ascites. A case report. Chin Med J (Engl) 1989;102:300-302.

4 Schumacher DL, Saclarides TJ, Staren ED. Peritoneovenous shunts for palliation of the patient with malignant ascites. Ann Surg Oncol 1994;1:378-381.

5 Lipsky MS, Sternbach MR. Evaluation and initial management of patients with ascites. Am Fam Physician 1996;54:1327-1333.

6 Alberts WM, Salem AJ, Solomon DA et al. Hepatic hydrothorax. Cause and management. Arch Intern Med 1991;151:2383-2388.

7 Sahn SA. Pleural diseases related to metastatic malignancies. Eur Respir J 1997;10:1907-1913.

8 Senger DR, Perruzzi CA, Feder J et al. A highly conserved vascular permeability factor secreted by a variety of human and rodent tumor cell lines. Cancer Res 1986;46:5629-5632.

9 Ferrara N, Henzel WJ. Pituitary follicular cells secrete a novel heparin-binding growth factor specific for vascular endothelial cells. Biochem Biophys Res Commun 1989;161:851-858.

10 Keck PJ, Hauser SD, Krivi G et al. Vascular permeability factor, an endothelial cell mitogen related to PDGF. Science 1989;246:1309-1312.

11 Neufeld G, Cohen T, Gengrinovitch S et al. Vascular endothelial growth factor (VEGF) and its receptors. FASEB J 1999;13:9-22.

12 Vaisman N, Gospodarowicz D, Neufeld G. Characterization of the receptors for vascular endothelial growth factor. J Biol Chem 1990;265:19461-19466.

13 De Vries C, Escobedo JA, Ueno H et al. The fms-like tyrosine kinase, a receptor for vascular endothelial growth factor. Science 1992;255:989-991.

14 Terman BI, Dougher-Vermazen M, Carrion ME et al. Identification of the KDR tyrosine kinase as a receptor for vascular endothelial cell growth factor. Biochem Biophys Res Commun 1992;187:1579-1586.

15 Waltenberger J, Claesson-Welsh L, Siegbahn A et al. Different signal transduction properties of KDR and Flt1, two receptors for vascular endothelial growth factor. J Biol Chem 1994;269:26988-26995.

16 Shalaby F, Rossant J, Yamaguchi TP et al. Failure of bloodisland formation and vasculogenesis in Flk-1-deficient mice. Nature 1995;376:62-66.

17 Millauer B, Shawver LK, Plate KH et al. Glioblastoma growth inhibited in vivo by a dominant-negative Flk-1 mutant. Nature 1994;367:576-579.
18 Nagy JA, Masse EM, Herzberg KT et al. Pathogenesis of ascites tumor growth: vascular permeability factor, vascular hyperpermeability, and ascites fluid accumulation. Cancer Res 1995;55:360-368.

19 Luo JC, Yamaguchi S, Shinkai A et al. Significant expression of vascular endothelial growth factor/vascular permeability factor in mouse ascites tumors. Cancer Res 1998;58:2652-2660.

20 Yano S, Shinohara H, Kuniyasu H et al. Formation of pleural effusion by human lung adenocarcinoma directly correlates with expression of VEGF/VPF. Proc Am Assoc Cancer Res 1999;40:227a

21 Luo JC, Toyoda M, Shibuya M. Differential inhibition of fluid accumulation and tumor growth in two mouse ascites tumors by an antivascular endothelial growth factor/permeability factor neutralizing antibody. Cancer Res 1998;58:2594-2600.

22 Mesiano S, Ferrara N, Jaffe RB. Role of vascular endothelial growth factor in ovarian cancer: inhibition of ascites formation by immunoneutralization. Am J Pathol 1998;153:1249-1256.

23 Zebrowski BK, Liu W, Ramirez K et al. Markedly elevated levels of vascular endothelial growth factor in malignant ascites. Ann Surg Oncol 1999;6:373-378.

24 Thickett DR, Armstrong L, Millar AB. Vascular endothelial growth factor (VEGF) in inflammatory and malignant pleural effusions. Thorax 1999;54:707-710.

25 Cheng D, Rodriguez RM, Perkett EA et al. Vascular endothelial growth factor in pleural fluid. Chest 1999;116:760-765.

26 Van Hinsbergh VWM, Draijer R. Culture and characterization of human endothelial cells. In: Shaw AJ, ed. Epithelial Cell Culture; A Practical Approach. New York, NY: Oxford University Press, 1996:87-110.

27 Westermann AM, Havik E, Postma FR et al. Malignant effusions contain lysophosphatidic acid (LPA)-like activity. Ann Oncol 1998;9:437-442.

28 Gawrychowski K, Skopinska-Rózewska E, Barcz E et al. Angiogenic activity and interleukin-8 content of human ovarian cancer ascites. Eur J Gynaecol Oncol 1998;19:262-264.

29 Harley RA. Pathology of pleural infections. Semin Respir Infect 1988;3:291-297.

30 Woodring JH, Vandiviere HM, Fried AM et al. Update: the radiographic features of pulmonary tuberculosis. AJR Am J Roentgenol 1986;146:497-506.

31 Hatipoglu ON, Osma E, Manisali M et al. High resolution computed tomographic findings in pulmonary tuberculosis. Thorax 1996;51:397-402.

32 Roberts WG, Palade GE. Neovasculature induced by vascular endothelial growth factor is fenestrated. Cancer Res 1997;57:765-772.

33 Esser S, Wolburg K, Wolburg H et al. Vascular endothelial growth factor induces endothelial fenestrations in vitro. J Cell Biol 1998;140:947-959. 
34 Dvorak HF, Nagy JA, Berse B et al. Vascular permeability factor, fibrin, and the pathogenesis of tumor stroma formation. Ann N Y Acad Sci 1992;667:101-111.

35 Brown LF, Olbricht SM, Berse B et al. Overexpression of vascular permeability factor (VPF/VEGF) and its endothelial cell receptors in delayed hypersensitivity skin reactions. J Immunol 1995;154:2801-2807.

36 Hazelton D, Nicosia RF, Nicosia SV. Vascular endothelial growth factor levels in ovarian cyst fluid correlate with malignancy. Clin Cancer Res 1999;5:823-829.
37 Verheul HMW, Hoekman K, Lupu F. Platelet and coagulation activation with vascular endothelial growth factor generation in soft tissue sarcomas. Clin Cancer Res 2000;6:166-171.

38 Fava RA, Olsen NJ, Spencer-Green G et al. Vascular permeability factor/endothelial growth factor (VPF/VEGF): accumulation and expression in human synovial fluids and rheumatoid synovial tissue. J Exp Med 1994;180:341-346.

39 Wang W, Merrill MJ, Borchardt RT. Vascular endothelial growth factor affects permeability of brain microvessel endothelial cells in vitro. Am J Physiol 1996;271:C1973-C1980. 